\title{
Response Surface Modelling of Diesel Engine Emissions under Variable Stroke Length and Constant Compression Ratio
}

\author{
Jehad A. A. Yamin ${ }^{1}$ \\ ${ }^{1}$ The University of Jordan, School of Engineering, Department of Mechanical Engineering, Amman 11942, Jordan. \\ Tel: 962-799-609-750. Fax: 962-6530-0813. E-mail: yamin@ju.edu.jo
}

Received: July 26, 2018

Accepted: August 8, 2018

Online Published: September 12, 2018

doi:10.5539/mas.v12n10p36

URL: https://doi.org/10.5539/mas.v12n10p36

\begin{abstract}
A theoretical investigation using RSM statistical technique on the relative change of emissions of a four-stroke, direct injection, water-cooled, 4-stroke, diesel engine with variable stroke length was carried out. The performance parameters were studied over wide range of speeds (1000 - 3000 RPM at an increment of 500 RPM) and stroke lengths (130 $\mathrm{mm}$ to $210 \mathrm{~mm}$ at an increment of $20 \mathrm{~mm})$. The compression ratio was kept constant by adjusting the piston bowl volume. It was found within the range of stroke length studied, that larger stroke lengths are favorable for lower NOx and specific $\mathrm{CO} 2$ emissions. This is due to the lower availability of Oxygen. As for specific PM and BSN, the shorter the stroke length the lower the levels. This is attributed to improved engine charging efficiency, hence, better availability of oxygen.
\end{abstract}

Keywords: Diesel Engine Simulation, Variable Stroke Length, DOE, RSM

\section{Introduction}

During the recent years, extensive research was conducted worldwide in the field of heavy duty diesel engines which resulted in significant improvement of engine performance and emissions. This research concentrated on two areas (1) improving the fuel quality and (2) modifying the engine design. As for the first area of research, great amount of work was conducted with the aim of either finding a replacement to diesel fuel or enhancing the qualities of the present diesel fuel. This study is related to the second category i.e. modifying the engine design. This area of research concentrated on trying to modify the existing design in order to improve the engine performance and emission characteristics. The use of the common-rail technique (Tanaka et al., 2004), changing the fuel injection rate (Desantes e al., 2004) and pressure (Hountalas et al., 2003), intake-port geometry (Corgard and Reitz, 2001), variable injection timing (Kouremenos etal., 2001), pre-and post-injection timing (Benajes et al., 2001), variable geometry turbocharging (Hawley et al., 1999), and many other techniques have all been investigated.

Again, each one has resulted in adding to the improvement of engine performance and emission characteristics, but with some penalty. One such techniques which was extensively investigated is the use of the variable stroke length or variable compression ratio (VCR) technique in the spark ignition (SI) engines (Yamin and Dado, 2004; Siewert, 1978) and the results have shown good improvement in the engine performance and emission characteristics within the range of speeds and bore-to-stroke ratios $(\mathrm{B} / \mathrm{S})$ covered. In this line, this study is a theoretical investigation in an attempt to shed some light on the effect of varying the stroke length with constant compression ratio, on the compression ignition engine performance using the Diesel-RK software (Kuleshov, 2005). Before starting to describe the main study, it's useful to explain something about the variable stroke engine.

The search for a feasible VCR engine has been driven by the compromise between WOT (Wide Open Throttle) and part-throttle which exists on any fixed compression ratio (CR) engine.

Detonation thresholds at WOT limit the maximum useable CR to a value lower than could be sustained at part throttle. Comparison of brake mean effective pressure (BMEP) shows that increasing CR becomes counterproductive at values typically above 11 12:1 since the reduction in spark advance negates the benefit from higher CR (Roberts, 2003).

Potential benefits in fuel consumption and carbon dioxide (CO2) emissions are, however, to be expected from running at higher $\mathrm{CR}$ during part throttle operation. The detonation limits identified at WOT do not apply to part throttle operation as the in-cylinder temperatures and pressures are so much lower. As the majority of engine running time occurs in this mode, real world improvements should be enabled, not just theoretical or experimental 
gains.

Patents have been filed and designs presented which modify the compression ratio by:

- Moving the cylinder head.

- Variation of combustion chamber volume.

- Variation of piston deck height.

- Modification of connecting rod geometry (usually by means of some intermediate member).

- Moving the crankpin within the crankshaft (effectively varying the stroke).

- Moving the crankshaft axis.

In many cases, the deviation from conventional production engine structure or layout represents a significant commercial barrier to widespread adoption of the technology.

Several parameters control the combustion characteristics of an engine, air-fuel ratio and compression ratio being two important ones (Pulkrabek, 2014). During the 1990s, the Saab Motor Company introduced an experimental engine with a unique, very promising design, which allows changing the compression ratio as the engine is running. This five-cylinder 1.6-liter SI engine has an engine block horizontally split at the center. The upper half of the block, called the monohead, contains the cylinders cast as a single unit with the head. The lower half contains the crankcase, crankshaft, and connected pistons. The two halves of the engine are connected on one side with a hinge connection, which allows the upper half to rotate up to 4 inches relative to the lower half. As the monohead rotates, it changes the size of the clearance volume of the cylinders at top dead center (TDC) and thus changes the compression ratio. With the engine running, the compression ratio can be varied anywhere from 8:1 for heavy loads to 14:1 for cruising at light load. The upper half of the engine is rotated with a large cam and a rubber bellows seals the two halves together.

Variable compression ratio engines have not yet reached the market, despite patents and experiments dating back over decades. Indeed, several prototypes of VCR engines and vehicles have been tested. In many cases, the deviation from conventional production engine structure or layout represents a significant commercial barrier to widespread adoption of the technology. Some of the commercial barriers are listed below (Shaik et al., 2007):

1. The available methods require major changes to the base engine architecture or layout and represent significant commercial barriers to wide-spread adoption of the technology.

2. Introduction of additional elements within the crowded combustion chamber environment threatens to compromise ideal geometry and layout of the valves and ports.

3. Engine-out emissions performance is likely to be undermined by additional crevice volumes which obstruct complete burning, thereby increasing hydrocarbon emissions.

4. There is a significant increase in reciprocating mass in the case of a variable height piston.

5. Some approaches lead to an increase in vibrations owing to intermediate members in the connecting rod.

6. In some cases, reworking of the entire engine structure is necessary.

7. Variable compression ratio designs consist of multilink rod-crank mechanisms, which may also present a nearto-sinusoidal motion unfavorable to cylinder filling at low speeds and fine-scale turbulence.

Another study (Muralidharan and Vasudevan, 2011) reported reduction of carbon monoxide, hydrocarbon and increase in nitrogen oxides emissions when using various biodiesel-Diesel blends in variable stroke diesel engine.

Further, (Yamin and Dado, 2004) reported improvement in a spark ignition variable stroke engine's (VSE) performance when using the VSE configuration compared with constant stroke engine.

Also, (Ozcan and Yamin, 2008) reported great advantage when using the VSE geometry for 4-stroke spark engines compared with conventional one.

\section{The Study}

In this study, the performance parameters were studied over speed range of (1000 rpm to $3000 \mathrm{rpm})$ and stroke lengths $(130 \mathrm{~mm}$ to $210 \mathrm{~mm})$ at constant compression ratio of $16.74: 1$ and injection timing at $20^{\circ}$ before TDC. The values of the stroke length, bore-to-stroke ratio and adjusted piston bowl volume are shown in Table (1). The cylinder diameter was $150 \mathrm{~mm}$. The basic design was at stroke length equals to $180 \mathrm{~mm}$ and bore-to-stroke length equals to 0.83 . The compression ratio was kept constant for every value of stroke length by adjusting the piston bowl volume. 
The shape of the piston used is shown below in figure (1) with the injector is centrally located and the clearance height between the tip of the flat piston surface and the cylinder head (hclr) is $3 \mathrm{~mm}$. The piston of the left is the final shape while the raw design is shown on the right hand side with top view showing the shape and distribution of the injected fuel.

Table 1. Stroke Length, Clearance and Bore-to-Stroke Length for Several Stroke Lengths

\begin{tabular}{ccc}
\hline $\begin{array}{c}\text { Stroke Length } \\
(\mathrm{mm})\end{array}$ & $\begin{array}{r}\text { Bore/Stroke Ratio } \\
{[\mathrm{ND}]}\end{array}$ & $\begin{array}{c}\text { Piston Bowl Volume } \\
\left(\mathrm{cm}^{3}\right)\end{array}$ \\
\hline 130 & 1.15 & 92.97 \\
150 & 1.00 & 115.37 \\
170 & 0.88 & 137.89 \\
180 & 0.83 & 149.10 \\
190 & 0.79 & 160.26 \\
210 & 0.71 & 182.68 \\
\hline
\end{tabular}
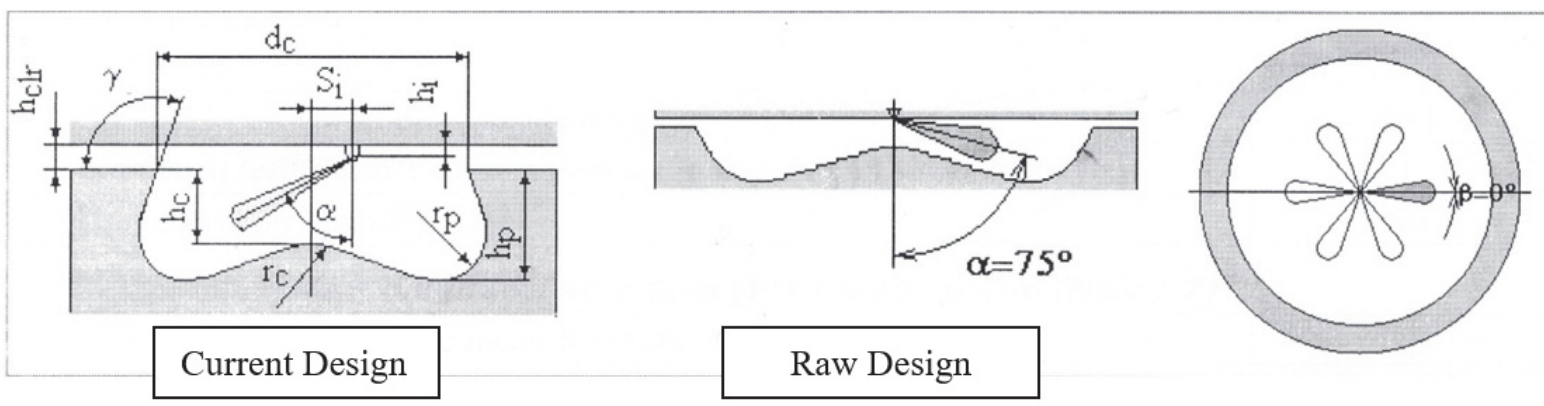

Figure 1. Piston configuration used in this study

The piston bowl has volume of $149068.852 \mathrm{~mm}^{3}$, while the flat clearance volume (Vclr) is $53014.376 \mathrm{~mm}^{3}$. This makes the total minimum volume of the engine equals to $202083.228 \mathrm{~mm}^{3}$.

\section{Results and Discussion}

The study focusses on the relative change in engine out emissions with variable displacement configuration compared with fixed stroke one. To understand the behavior, certain parameters were also studied to understand the results. These parameters were; mass of air and fuel induced, thermal efficiency, maximum cylinder and exhaust temperatures.

\subsection{Parametric Analysis}

The effect of stroke length on the engine's exhaust emissions is shown in Table (2). The table shows the relative change in engine emissions and their affecting parameters as a function of percentage change in stroke length. The positive value means increase in parameter and the negative one means decrease in value. The values shown are for both low and high engine speeds.

At low engine speeds, oxides of nitrogen (NOx) and CO2 levels are nearly at their best value (minimum) around the original design, with slight edge for increasing the stroke length (under-square design). The reduction in the maximum cylinder temperature, as well as the higher cylinder temperatures at exhaust valve opening time, in addition to lower oxygen availability at slightly higher stroke lengths (under-square design) and the higher heat loss values due to larger surface area, causes the $\mathrm{NOx}$ and $\mathrm{CO}_{2}$ values to drop down. This case is reversed at lower stroke values.

As for the Bosch smoke number (BSN) and particulate matter (PM) values, the case is opposite to other pollutants. Their values are least at shorter stroke lengths. This is due to the higher oxygen availability (shown by volumetric efficiency) at shorter stroke lengths, causes the fuel to burn in a complete manner, hence, reduction in incomplete combustion pollutants e.g. PM and BSN. 
Table 2. Summery of relative change in engine parameters with respect to original design

\begin{tabular}{|c|c|c|c|c|c|c|}
\hline \multirow{2}{*}{$\begin{array}{l}\text { Performance } \\
\text { Parameter }\end{array}$} & \multicolumn{6}{|c|}{ Percentage Change in Stroke Length Values } \\
\hline & -27.78 & -16.67 & -5.56 & 0.00 & 5.56 & 16.67 \\
\hline \multicolumn{7}{|c|}{ At 1000 RPM } \\
\hline Air mass flow rate & -28.88 & -17.48 & -5.88 & 0.00 & 5.93 & 18.19 \\
\hline Fuel & -28.81 & -17 & -5.87 & 0.00 & 5.91 & 18.14 \\
\hline Peak cylinder Temp & 1.66 & & 0.36 & 0.00 & -0.26 & -3.17 \\
\hline Exhaust Temp & -4.66 & -2 & -0.78 & 0.00 & 0.76 & 3.78 \\
\hline Hea & -13.29 & -7 & -2.69 & 0.00 & 3.09 & 7.14 \\
\hline c Efficiency & 0.50 & & & 0.00 & -0.19 & -0.57 \\
\hline Brake Power & -28.97 & & -5.48 & 0.00 & 5.19 & 14.86 \\
\hline Specific $\mathrm{CO}_{2}$ level & 2.47 & & & 0.00 & 0.10 & 1.00 \\
\hline $\mathrm{NOx}$ & 3.64 & & 3 & 0.00 & -2.62 & -16.50 \\
\hline Bos & -26.29 & & -6 & 0.00 & 5.84 & 09 \\
\hline & -30.18 & -23.29 & -7.64 & .00 & .48 & 77.80 \\
\hline \multicolumn{7}{|c|}{ At 3000 RPM } \\
\hline Air 1 & -36.01 & & -10.51 & 0.00 & 14.45 & 68.82 \\
\hline Fuel mass flow rate & -36.56 & -25.65 & -10.75 & 0.00 & 14.82 & 70.65 \\
\hline Peak cylinder Temp & 1.16 & 1.09 & 0.45 & 0.00 & -0.20 & -0.13 \\
\hline Exhaust Temp & -1.21 & -0.71 & -0.23 & 0.00 & 0.00 & -0.27 \\
\hline Heat Loss & -14.58 & -7.75 & -2.68 & 0.00 & 3.18 & 9.47 \\
\hline Volumetric Efficiency & 33.40 & 19.95 & 6.28 & 0.00 & -5.75 & -16.20 \\
\hline Brake Power & 47.90 & 35.02 & 13.37 & 0.00 & -13.87 & -43.94 \\
\hline Specific $\mathrm{CO}_{2}$ level & -34.82 & -26.09 & -11.43 & 0.00 & 15.60 & 74.83 \\
\hline NOx & 40.33 & 31.07 & 10.89 & 0.00 & -6.81 & -22.54 \\
\hline Bosch & -30.55 & -20 & -7.35 & 0.00 & 4.81 & 13.09 \\
\hline Specific PM & -60.53 & -46.19 & -20.41 & 0.00 & 23.40 & 107.28 \\
\hline
\end{tabular}

The same behavior, but at different scale is noticed from the same table at higher engine speeds. Incomplete combustion-related pollutants (e.g. BSN and PM) increase significantly at higher engine speeds and larger stroke lengths. The large reduction in volumetric efficiency resulted in oxygen deficiency hence incomplete combustion. This causes the NOx values to be lower. The increment in $\mathrm{CO} 2$ level maybe attributed to significant reduction in engine power at larger stroke lengths, hence, specific $\mathrm{CO} 2$ values increase.

Further noticed, is the disproportionate between the percentage changes in stroke length compared with that of the engine parameters.

The largest change being for the PM and CO2 at lower speeds. For higher speed, all the emissions studied showed higher levels of change compared with the change in stroke length.

\subsection{Statistical Analysis}

Below is the result obtained from the analysis of the data, statistically, using the Response Surface Method (RSM) technique. The figures shown below are called Pareto charts. These types of charts shows the parameters that has the most or least significant effect on certain variable. The larger the value of the factor the most significant its effect is. Figures (2) below represent the effect of engine speed, stroke length and their interaction levels on the engine parameter. For this study, the effect on engine emissions only are shown. 


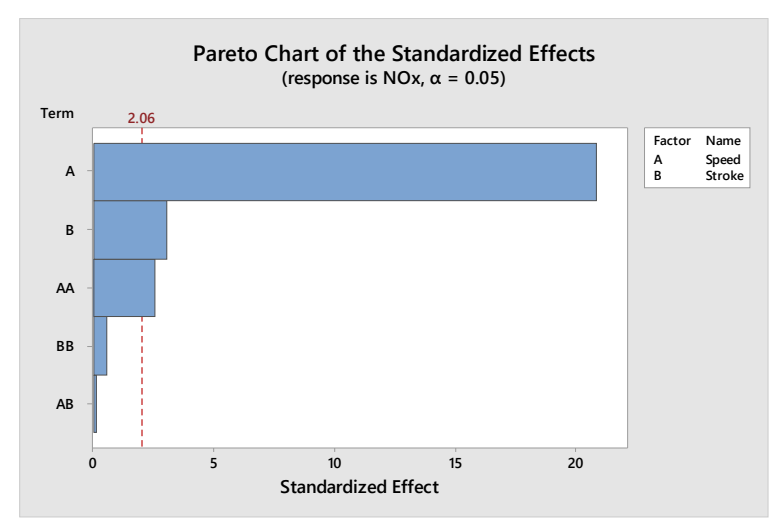

(a) NOx

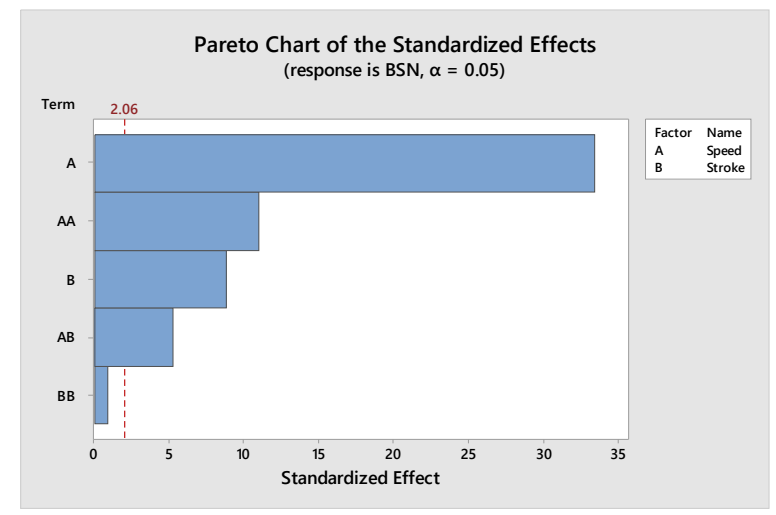

(c) $\mathrm{BSN}$

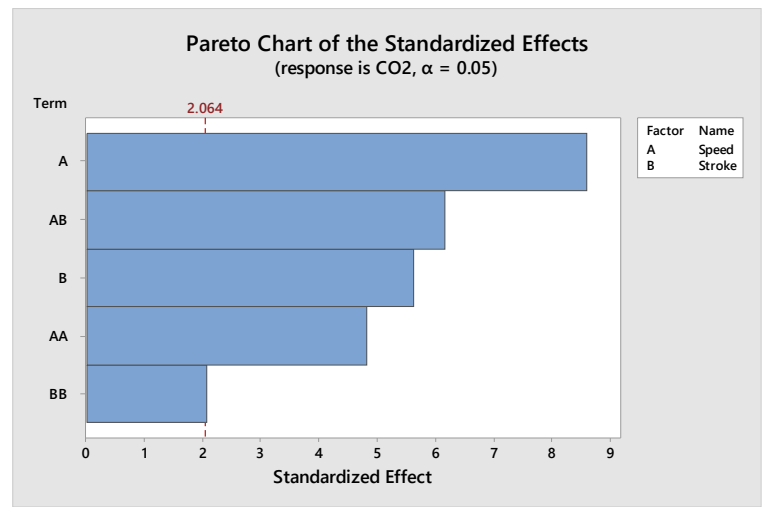

(b) $\mathrm{CO}_{2}$

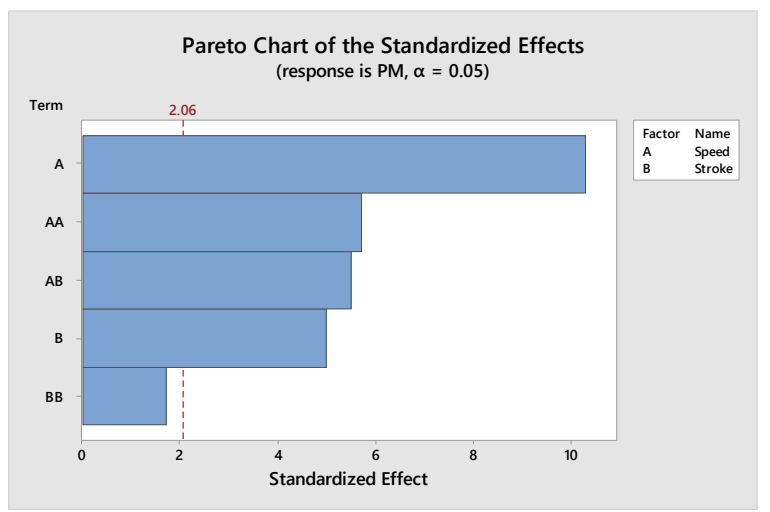

(d) PM

Figure 2. Pareto chart for factors' effect on engine emissions

First thing noticed is that the engine speed has the most significant effect on those emissions. It has greater effect on BSN and NOx emissions in a greater degree than other emissions. On the other hand, stroke length has lower degree of effect on the variables compared with engine speed, but, it affects engine $\mathrm{CO} 2$ and PM in greater manner than other emissions.

For the case of NOx, the stroke length, its interaction with engine speed and its two way levels are all insignificant. Hence, the model proposed for the NOx effect shown in equation (1), which has fairly good degree of accuracy as shown in Table (3), can be reduced by removing these terms.

NOx $=2199-0.145$ Speed +3.5 Stroke -0.000147 Speed*Speed -0.0197 Stroke*Stroke +1.7 e-4 Speed*Stroke

Specific Carbon dioxide level, is influenced by all the factors and their two-way interactions. Hence, both factors affect $\mathrm{CO} 2$ level in the exhaust. Stroke length to power of two has lest significant on the CO2 level. The model proposed by this method, shown by equation (2) has good degree of accuracy.

$$
\begin{gathered}
\mathrm{CO} 2=5150-2.121 \text { Speed }-35.3 \text { Stroke }+0.000269 \text { Speed*Speed } \\
+0.0728 \text { Stroke*Stroke+ } 7.82 \mathrm{e}-3 \text { Speed*Stroke }
\end{gathered}
$$

Bosch Smoke Number, follows the same trend as that for $\mathrm{CO} 2$, but, to less degree. The equation developed can also be reduced without sacrificing its accuracy by neglecting the effect of stroke length to power of two. This is shown in equation (3).

$\mathrm{BSN}=3.05-0.002414$ Speed -0.0155 Stroke +0.000001 Speed*Speed $+3 \mathrm{e}-5$ Stroke*Stroke $\quad+7 \mathrm{e}-$ 6 Speed*Stroke

Specific Particulate Matter, follows the same trend as hat for CO2, however, the effect of stroke length to higher powers are insignificant. The model predicted by this method is shown below.

$\mathrm{PM}=7.78-0.004105$ Speed -0.0582 Stroke +0.000001 Speed*Speed +0.000117 Stroke*Stroke+ $1.4 \mathrm{e}-$ 
5 Speed*Stroke

Table 3. Model Accuracy Summary

\begin{tabular}{ccccc}
\hline Parameter & S & R-sq & R-sq(adj) & R-sq(pred) \\
\hline NOx & 130.583 & $94.97 \%$ & $93.92 \%$ & $90.55 \%$ \\
CO2 & 128.187 & $88.07 \%$ & $85.58 \%$ & $70.60 \%$ \\
BSN & 0.124527 & $98.28 \%$ & $97.93 \%$ & $96.33 \%$ \\
PM & 0.248019 & $89.46 \%$ & $87.27 \%$ & $74.74 \%$ \\
\hline
\end{tabular}

\section{Conclusions}

Within the range of $\mathrm{B} / \mathrm{S}$ ratios studied, it can be conclude that:

1. Engine speed has the most significant effect on all emissions.

2. There is noticeable increase in the NOx levels with shorter stroke lengths while other emissions tend to increase at larger stroke lengths.

\section{Acknowledment}

The author would like to offer special thanks to Dr. A.S. Kuleshov for granting his approval to use the Diesel-RK software and data for publication.

\section{References}

Benajes, J., Molina, S., \& García, J. M. (2001). Influence of pre-and post-injection on the performance and pollutant emissions in a HD diesel engine (No. 2001-01-0526). SAE technical paper. https://doi.org/10.4271/2001-01-0526

Corgard, D. D., \& Reitz, R. D. (2001). Effects of alternative fuels and intake port geometry on HSDI diesel engine performance and emissions (No. 2001-01-0647). SAE Technical Paper. https://doi.org/10.4271/2001-01-0647

Desantes, J. M., Benajes, J., Molina, S., \& Gonzalez, C. A. (2004). The modification of the fuel injection rate in heavy-duty diesel engines. Part 1: Effects on engine performance and emissions. Applied Thermal Engineering, 24(17-18), 2701-2714. https://doi.org/10.1016/j.applthermaleng.2004.05.003

Hawley, H. G., Wallace, F. J., \& Cox, A. (1999). The demonstration of variable geometry turbocharging for improved engine performance. Proceedings of the Asia-Pacific international symposium on combustion and energy utilization, 5th, Shanghai, China, Oct. 24-29, 314-321.

Hountalas, D. T., Kouremenos, D. A., Binder, K. B., Schwarz, V., \& Mavropoulos, G. C. (2003). Effect of injection pressure on the performance and exhaust emissions of a heavy duty DI diesel engine (No. 2003-010340). SAE Technical Paper. https://doi.org/10.4271/2003-01-0340

Kouremenos, D. A., Hountalas, D. T., Binder, K. B., Raab, A., \& Schnabel, M. H. (2001). Using advanced injection timing and EGR to improve DI diesel engine efficiency at acceptable NO and soot levels (No. 200101-0199). SAE Technical Paper. https://doi.org/10.4271/2001-01-0199

Kuleshov, A. S. (2005). Model for predicting air-fuel mixing, combustion and emissions in DI diesel engines over whole operating range (No. 2005-01-2119). SAE Technical Paper. https://doi.org/10.4271/2005-01-2119

Muralidharan, K., \& Vasudevan, D. (2011). Performance, emission and combustion characteristics of a variable compression ratio engine using methyl esters of waste cooking oil and diesel blends. Applied Energy, 88(11), 3959-3968. https://doi.org/10.1016/j.apenergy.2011.04.014

Ozcan, H., \& Yamin, J. A. (2008). Performance and emission characteristics of LPG powered four stroke SI engine under variable stroke length and compression ratio. Energy Conversion and Management, 49(5), 1193-1201. https://doi.org/10.1016/j.enconman.2007.09.004

Pulkrabek, W. W. (2014). Engineering fundamentals of the internal combustion engine. Upper Saddle River: Pearson Prentice Hall.

Roberts, M. (2003). Benefits and challenges of variable compression ratio (VCR) (No. 2003-01-0398). SAE Technical Paper. https://doi.org/10.4271/2003-01-0398

Shaik, A., Moorthi, N. S. V., \& Rudramoorthy, R. (2007). Variable compression ratio engine: A future power plant 
for automobiles-an overview. Proceedings of the Institution of Mechanical Engineers, Part D: Journal of Automobile Engineering, 221(9), 1159-1168. https://doi.org/10.1243/09544070JAUTO573

Siewert, R. M. (1978). Engine combustion at large bore-to-stroke ratios. SAE Transactions, 3637-3651.

Tanaka, Y., and Jagata, K. (2004). 1800 bar common rail system for diesel engine. First Dep. Of Jet Technology, Denso Diesel Co., Ltd., Kariya, Japan. Jidosa Gijutsu, 58(4), pp.19-24, 2004.

Yamin, J. A., \& Dado, M. H. (2004). Performance simulation of a four-stroke engine with variable stroke-length and compression ratio. Applied Energy, 77(4), 447-463. https://doi.org/10.1016/S0306-2619(03)00004-7

\section{Copyrights}

Copyright for this article is retained by the author(s), with first publication rights granted to the journal.

This is an open-access article distributed under the terms and conditions of the Creative Commons Attribution license (http://creativecommons.org/licenses/by/4.0/). 